ПОНЯТИЕ, ПРИЗНАКИ И РОЛЬ СУДЕБНОЙ СИСТЕМЫ В РАЗВИТИИ РОССИЙСКОГО ОБЩЕСТВА

\author{
Бабаев Айдын Ажндарович \\ магистрант 2 курса Юридического института \\ Дагестанского госуниверситета
}

\title{
CONCEPT, CHARACTERISTICS AND ROLE OF THE JUDICIAL SYSTEM IN THE DEVELOPMENT OF THE RUSSIAN SOCIETY
}

\author{
Babaev Aydin Azhdarovich \\ 2-year undergraduate of the Law Institute \\ of Dagestan State University \\ DOI: 10.31618/ESU.2413-9335.2020.4.75.848
}

АННОТАЦИЯ

В статье рассматриваются подходы к пониманию судебной системы в российской юридической науке, роль судебной системы в развитии современного российского общества, а также дается характеристика ее признаков, позволяющих обозначить институциональные и функциональные особенности: исключительность судебной системы в осуществлении правосудия; единство и целостность; многофункциональность; мультиструктурность и ступенчатость; многоуровневый и многоканальный характер взаимосвязи между элементами; стабильность и устойчивость; самостоятельность и независимость в механизме государства.

\section{RESUME}

The article discusses approaches to understanding the judicial system in Russian legal science, the role of the judicial system in the development of modern Russian society, as well as the characteristics of its features, allowing to identify the institutional and functional features: the exclusivity of the judicial system in the administration of justice; unity and integrity; multifunctionality; multi-structure and stepping; multi-level and multi-channel nature of the relationship between the elements; stability and sustainability; independence and independence in the mechanism of the state.

Ключевые слова: судебная система, судебная власть, правосудие, механизм государства, судебная реформа.

Key words: judicial system, judicial power, justice, state mechanism, judicial reform.

Роль судебной системы в цивилизованном развитии общества трудно переоценить. Ее функционирование обеспечивает реализацию не только принципов демократии, прав и свобод личности, верховенство права, но также и общественный контроль за деятельностью институтов публичной власти для пресечения их произвола, гражданского общества и населения при разрешении разнообразных конфликтов ${ }^{1}$.

Следует заметить, что в дореволюционный период в российской юридической науке понятие судебной системы не рассматривалось, ученые оперировали преимущественно понятием судебная власть, при этом отдельными русскими правоведами она могла приравниваться к судебному решению ${ }^{2}$. В современной науке можно выделить три основных подхода к пониманию судебной системы.

1 Бекишиева С.P. Правовое государство и верховенство права: проблемы соотношения и практического воплощения в российской правовой системе // Юридический вестник ДГУ. 2017. Т. 23. № 3. С. 18-25.

${ }^{2}$ Градовский А. Начала русского государственного права. Т. 1. Спб., 1875. С. 74.

${ }^{3}$ Колоколов Н.А., Павликов С.Г. Теория судебных систем: особенности конституционного
Большинство ученых сходятся во мнении, что судебная система преставляет собой совокупность определенных судебных органов. Например, Н.А.Колоколов и С.Г.Павликов утверждают, что данная система включает в себя только аппарат судебной власти - судей и суды. Каждое звено судебной системы при этом включает такие составные части ее структуры, которые в единое целое объединяют «группы судов, отличающиеся друг от друга только по деятельному (юрисдикционно-процессуальному) признаку» ${ }^{3}$.

Некоторые авторы дополняют такое институциональное определение поименным обозначением тех судов, которые входят в судебную систему данного государства ${ }^{4}$. Иногда помимо действующих судов в судебную систему включают также органы управления судебной системой ${ }^{5}$. Следует подчеркнуть, что такой подход противоречит действующему российскому

$\begin{array}{llll}\text { регулирования, судебного строительства } & \text { и } \\ \text { организации } & \text { судебной } & \text { деятельности } & \text { в }\end{array}$ федеративном государстве. М., 2007. С. 198.

4 Клеандров М.И. Судья - центральное звено судебной системы. М., 2004. С. 7-8.

5 Струсь К.А. Гражданское общество и государство: генезис идеи и современная Россия // Новая правовая мысль. 2003. № 8. 
законодательству, называющему в судебной системе РФ в качестве ее составных элементов только суды. Органы управления судебной системой хотя и призваны обеспечивать реализацию главной функции судебных органов осуществление правосудия, но сами не вправе ни отправлять правосудие, ни вмешиваться в его отправление. Их предназначение четко обозначено в законодательстве и состоит в создании необходимых «условий для обеспечения доступности правосудия для граждан, укрепление самостоятельности судов и независимости судей».

Можно также упомянуть авторов, считающих необходимым обозначить в определении несколько признаков судебной системы, которые представляются им важными, например, С.Л.Разумов рассматривает ее как «совокупность федеральных судов и судов субъектов РФ, входящих в единую судебную систему, имеющих общие задачи, принципы организации и деятельности по осуществлению правосудия и реализующих посредством правосудия самостоятельную судебную власть, действующих независимо от законодательной и исполнительной властей» ${ }^{6}$.

Следует отметить, что институциональный подход к пониманию судебной системы раскрывает ее содержание исключительно как элемента государственного механизма, ракрывая особенности национального судоустройства, связанного с формой государственнотерриториального устройства страны. Представленный в современном российском законодательстве подход считается в юридической науке конструктивным и прагматичным, поскольку он позволяет акцентировать внимание исследователя и правоприменителя на организационно-функциональном аспекте судебной системы.

В современной российской юридической науке представлен также подход к пониманию и структуре судебной системы, представители которого идут по пути значительного расширения элементного состава рассматриваемой системной категории. К примеру, А.В.Никитина в структуре судебной системы рассматривает составные части не только организационного, но и идеологического и коммуникативного характера, среди которых автором перечисляются: «принципы организации судебной системы; органы управления судебной системой; органы судейского сообщества; судейский корпус, в широком понимании состоящий из судей как носителей судебной власти, судей в отставке, народных, присяжных, арбитражных заседателей; совокупность

6 Разумов С.Л. Понятие судебной системы // Судебная система России. М., 2000. С. 114.

7 Никитина А.В. Единство судебной системы Российской Федерации (конституционно-правовое исследование): автореф. дис. ... канд. юрид. наук. Омск, 2006. С. 16. разнообразных связей и отношений между данными элементами» ${ }^{7}$. Сходную позицию по рассматриваемому вопросу занимает Ю.М.Гайдидей, определяя в качестве составных элементов судебной системы следующие взаимосвязанные институциональные, функциональные нормативные и идеологические компоненты: «система судов как центральный элемент судебной системы; судейский корпус; органы судейского сообщества; третейские суды; работники аппаратов судов; арбитражных и присяжных заседателей; судебно-правовая культура; судебное и судейское право» ${ }^{8}$.

Такая позиция основана на характеристике судебной системы прежде всего как системной категории, в которой структурные элементы не могут существовать обособленно, функционировать автономно, независимо друг от друга. Изменение хотя бы одного из элементов такого образования неизбежно приводит к общим и частным изменениям в системе, что поддерживает ее единство и целостность. Однако такая широкая трактовка судебной системы обоснованно критикуется в науке. По мнению Э.Р.Рубининой, очень широкая интерпретация рассматриваемой категории «не отражает подчиненность задач, принципов организации и деятельности судебных органов общей цели деятельности судебной системы - обеспечению правосудия» ${ }^{9}$.

На наш взгляд, любой из подходов к исследованию системной категории должен основываться на учете реализации ее элементами общих функций, достижения общих целей и решения общих задач, что невозможно при выпадении любого из ее составных элементов. Поэтому даже широкий подход к пониманию судебной системы должен иметь границы и четкое обоснование ее единства и целостности.

Таким образом, можно утверждать, что в современной российской юридической науке сложились два основных подхода к пониманию судебной системы:

1. узкий подход, акцентирующий внимание на судоустройстве, то есть организационнофункциональном аспекте судебной системы, и определяющий ее как совокупность судебных органов, осуществляющих правосудие;

2. широкий подход, отличающийся в рассмотрении судебной системы множественностью ее структурных компонентов и раскрывающий не только организационнофункциональный ее аспект, но и нормативную, идеологическую, коммуникативную стороны, уровни, аспекты.

${ }^{8}$ Гадидей Ю.М. Судебная система в современной России: общетеоретический аспект: дис. ... канд. юрид. наук. Краснодар, 2012. С. 9.

9 Рубинина Э.Р. Понятие судебной системы современной России: новые подходы // Юридическая наука и правоохранительная практика. 2016. № 1 (35). С. 185. 184-193. 
Определение судебной системы легально не закреплено в законодательстве РФ, но она представлена в виде упорядоченной организации системы судов, функционирующих на основе общих принципов, что позволяет считать узкий подход к пониманию судебной системы представленным российским законодателем. Данный подход, следует признать, также более удобен с практической точки зрения, поскольку акцентирует внимание, во-первых, на общности принципов, обеспечивающих единство в такой системе, в которой составные части различаются предметной компетенцией, объемом судебной власти и кругом полномочий; во-вторых, на общности их задач, что также обеспечивает единство системы с учетом федеративной формы государственного устройства России.

Таким образом, судебную систему России можно определить как совокупность федеральных судов и судов субъектов Российской Федерации, объединенных общностью задач и принципов организации и деятельности по осуществлению правосудия.

Спорным в современной российской юридической науке является вопрос также о признаках, отличительных свойствах судебной системы. В данном случае представляется важным сравнение судебной системы с другими системными категориями государственного механизма, а также с несистемными понятиями, так или иначе имеющющими отношение к судебной системе.

Среди признаков судебной системы России представляется необходимым обозначить следующие ее институциональные и функциональные особенности.

1. Суд выступает главным и единственным элементом судебной системы России, поскольку представляет собой именно ту минимальную ее часть, которая функционально демонстрирует общие основные закономерности системы в целом. В данном теоретическом положении мы солидарны с А.Н.Чашиным, по мнению которого элементом судебной системы может быть только тот субъект правового отношения, который наделен правом на осуществление правосудия ${ }^{10}$, что показывает такую важную закономерность судебной системы, как ее функциональное назначение. Некоторые авторы обозначают рассматриваемое свойство судебной системы как ее исключительность, которая «раскрывается в отправлении правосудия только судами и обязательности судебных постановлений, вступивших в законную силу» ${ }^{11}$. В любом случае в современной России судебные органы как носители судебной власти обладают монопольным правом на осуществление правосудия.

2. Судебной системе России характерна многофункциональность, связанная с тем, что она включает имеющие различную специализацию

10 Чашин А.Н. Судебная система и судебная реформа. М.: Дело и сервис, 2014. судебные органы, деятельность которых направлена на обеспечение конституционных устоев, охрану законных прав и интересов граждан и организаций в разнообразных сферах общественной жизни. В Российской Федерации судебная система включает следующие виды судов: конституционные суды, суды общей юрисдикции, арбитражные суды.

3. Взаимосвязанными признаками российской судебной системы являются ее мультиструктурность и ступенчатость (иерархичность). Мультиструктурность судебной системы тесно связана с еe многофункциональностью и демонстрирует тот факт, что в судебной системе РФ параллельно функционируют следующие подсистемы: Конституционный Суд РФ, система судов общей юрисдикции и система арбитражных судов во главе с Верховным Судом РФ (в которых четко наблюдается ступенчатость судебной системы), а также суды субъектов РФ - конституционные (уставные) суды и мировые суды. Мировой суд занимает двойственное положение в отечественной судебной системе, поскольку хотя он и был учрежден в качестве суда субъекта Федерации, но по сути выступает элементом федеральной судебной системы, входящим в нее в качестве низшего звена системы судов общей юрисдикции ее первой судебной инстанции.

4. Судебная система России, несмотря на федеративный характер ее государственнотерриториального устройства, имеет качество единой и целостной системы. Единство судебной системы обусловлено единством нормативноправовой основы еe функционирования, наделением всех судей страны единым правовым статусом, обеспечением финансирования судебной системы из единого источника - государственного бюджета, а также признанием единого статуса постановлений всех судебных органов. Качество единства судебной системы России не отменяется федеративным характером ее государственнотерриториального устройства, несмотря на существующую дезинтеграцию системы, что должно быть преодолено, на наш взгляд, в ходе дальнейшего развития судебной реформы в России. Единство судебной системы также обусловлено ее общей функциональной направленностью. Целостность судебной системы тоже вытекает из ее единства, но при этом еще и показывает, что только совокупность всех федеральных судов и судов субъектов Федерации способна обеспечить в полном объеме осуществление правосудия в стране, то есть выполнять то общее назначение всех судов единой системы - защищать права и свободы личности, которое часто не может в завершенном виде выполнить суд нижестоящего звена в отдельности, до возникновения необходимой

11 Огадзе А.А. Конституционно-правовые основы судебной системы Российской Федерации: Автореф. дис. ... канд. юрид. наук. М., 2013. С. 8. 
системной взаимосвязи между судебными инстанциями.

5. Взаимосвязь между судами РФ носит многоуровневый и многоканальный характер, поскольку они находятся в разнообразных отношениях, что придает судебной системе характер стабильного образования, сохраняющего свою устойчивость в условиях затянувшейся судебной реформы. Звенья судебной системы состоят из судов первой, апелляционной, кассационной и надзорной инстанций. Исследователями и практиками признается тот факт, что «судебные системы с тремя и четырьмя связями обладают стабильностью и оптимальным объемом качеств» ${ }^{12}$. Несмотря на продолжающееся реформирование судоустройства и судопроизводства, направленное на укрепление независимости и самостоятельности судебной системы страны, она продолжает сохранять свою стабильность и устойчивость, которые в том числе обусловлены ее конституционным закреплением в Основном законе страны и основанном на нем ФКЗ «О судебной системе Российской Федерации», а также запретом создания таких судебных органов, которые прямо не предусмотрены ими.

6. Судебная система РФ носит самостоятельный характер, что вытекает из специфического характера властных полномочий судов, которые независимы в своей деятельности от других элементов государственного механизма. Законодательные и исполнительные органы могут только обеспечивать организацию правосудия и финансирование его осуществления, что ни в коем случае не нарушает автономности функционирования судебной системы. Ее независимость проявляется и в наличии властных полномочий в отношении органов законодательной и исполнительной власти, в частности, к ним относятся полномочия судов по признанию недействительными правовых актов (нормативных и индивидуальных), нарушающих права и свободы личности или противоречащих актам более высокой юридической силы. Кроме того самостоятельность судебной системы заключается не только в функционировании независимо от чьейлибо воли, но и подчинение судов только российской Конституции и законодательству. Конечно, автономность функционирования судебной системы не отменяет ее взаимосвязи с окружающей средой, иными социальными системами - гражданским обществом, государством, правовой системой в целом, которые оказывают влияние на ее развитие, но данная взаимосвязь исключает непосредственную подчиненность судебной системы в отправлении правосудия различным субъективным факторам и органичивается ее подчинением закону и закрепленным в нем принципам, отражающим объективные закономерности развития правовой сферы жизни общества.

12 Яровая М.В. Судебные системы современных европейских государств: сравнительно-правовой
Таким образом, подводя итоги исследования, можно сформулировать ряд выводов.

1. В российской юридической науке сложились два основных подхода к пониманию судебной системы: во-первых, узкий подход, акцентирующий внимание на организационнофункциональном аспекте судебной системы и определяющий ее как совокупность судебных органов, осуществляющих правосудие; во-вторых, широкий подход, отличающийся в рассмотрении судебной системы множественностью ее структурных компонентов и раскрывающий не только организационно-функциональный еe аспект, но и нормативную, идеологическую, коммуникативную стороны, уровни.

2. Узкий подход к пониманию судебной системы представляется более удобным с практической точки зрения, т.к. акцентирует внимание, во-первых, на общности принципов, обеспечивающих единство в системе, в которой составные части различаются предметной компетенцией, объемом судебной власти и кругом полномочий; во-вторых, на общности их задач, что также обеспечивает единство системы с учетом федеративной формы государственного устройства. Судебную систему России можно определить как совокупность федеральных судов и судов субъектов РФ, объединенных общностью задач и принципов организации и деятельности по осуществлению правосудия.

3. Сравнение судебной системы России с другими системными и несистемными понятиями, позволяет выделить следующие ее признаки: исключительность судебной системы в осуществлении правосудия; единство и целостность; многофункциональность; мультиструктурность и ступенчатость; многоуровневый и многоканальный характер взаимосвязи между элементами судебной системы; ее стабильность и устойчивость; самостоятельность и независимость в механизме государства.

Пристатейный библиографический список

1.Бекишиева С.Р. Правовое государство и верховенство права: проблемы соотношения и практического воплощения в российской правовой системе // Юридический вестник ДГУ. 2017. Т. 23. № 3. С. 18-25.

2.Гадидей Ю.М. Судебная система в современной России: общетеоретический аспект: дис. ... канд. юрид. наук. Краснодар, 2012.

3.Градовский А. Начала русского государственного права. Т. 1. Спб., 1875.

4.Клеандров М.И. Судья - центральное звено судебной системы. М., 2004.

5.Колоколов Н.А., Павликов С.Г. Теория судебных систем: особенности конституционного регулирования, судебного строительства и организации судебной деятельности в

анализ: Автореф. дисс. ... канд. юрид. наук. М., 2006. C. 11. 
федеративном государстве. М., 2007.

6.Никитина А.В. Единство судебной системы Российской Федерации (конституционно-правовое исследование): автореф. дис. ... канд. юрид. наук. Омск, 2006.

7.Огадзе А.А. Конституционно-правовые основы судебной системы Российской Федерации: Автореф. дис. ... канд. юрид. наук. М., 2013.

8.Разумов С.Л. Понятие судебной системы // Судебная система России. М., 2000.

9.Рубинина Э.Р. Понятие судебной системы современной России: новые подходы //
Юридическая наука и правоохранительная практика. 2016. № 1 (35). С. 185. 184-193.

10.Струсь К.А. Гражданское общество и государство: генезис идеи и современная Россия // Новая правовая мысль. 2003. № 8.

11.Чашин А.Н. Судебная система и судебная реформа. М.: Дело и сервис, 2014.

12.Яровая М.В. Судебные системы современных европейских государств: сравнительно-правовой анализ: Автореф. дисс. ... канд. юрид. наук. М., 2006.

\section{АКТУАЛЬНЫЕ ПРОБЛЕМЫ УГОЛОВНО-ПРАВОВОЙ РЕГЛАМЕНТАЦИИ ОТВЕТСТВЕННОСТИ ЗА ХИЩЕНИЕ ПРЕДМЕТОВ, ИМЕЮЩИХ ОСОБУЮ ЦЕННОСТЬ: СОВРЕМЕННОЕ СОСТОЯНИЕ И ПЕРСПЕКТИВЫ}

\section{АННОТАЦИЯ}

Давлетов Эмиль Рустемович магистрант кафедры уголовного права и криминологии, Юридический факультет им. А.А. Хмырова, Кубанский государственный университет, Краснодар, Российская Федераџия.

В статье рассматриваются дискуссионные в теории уголовного права вопросы, касающиеся особенностей законодательного описания объекта и предмета хищения предметов, имеющих особую ценность. Анализируются научные точки зрения на проблему реализации уголовного законодательства в области охраны культурных ценностей, формулируются предложения по повышению его эффективности. Даётся определение понятия «культурные ценности» а также обозначена проблема и перспективы развития разграничения слитых воедино законодателем форм соучастия, использованных для формирования квалифицированного состава хищения предметов имеющих особую ценность.

Ключевые слова: преступления против собственности, хищение культурных ценностей, предметы имеющие особую ценность, культурные ценности, предмет, вопросы квалификации.

В российском государстве на современном этапе его развития проблема сохранения предметов, представляющих особую культурную, историческую и иную ценность, является крайне актуальной. Причем дело не только в количестве совершаемых преступлений, хотя этот фактор является немаловажным, а в предмете посягательств. Последний в свою очередь вызывает много проблем и трудностей, как с точки зрения уголовно-правового понимания и уяснения, так и с точки зрения невосполнимости тех предметов, которые были похищены. Противоправное, безвозмездное изъятие данных предметов на сегодняшний день является одним из устойчивых направлений организованной преступности, которая в свою очередь приносит неимоверные доходы и наносит колоссальный ущерб мировому культурному достоянию.

Ценность и значимость указанных предметов для развития цивилизации, их уникальный и невосполнимый характер, роль в развитии личности, духовности и культуры общества создают социальные предпосылки для придания такому хищению особого статуса, для

13 Щерба С.П., Приданов С.А. Уголовно-правовая охрана предметов и документов, имеющих историческую, научную, художественную или формирования отдельных норм, предусматривающих ответственность за него ${ }^{13}$.

Анализируя состав данного преступления, приходим к выводу, что некоторые его признаки требуют дополнительного, более глубокого исследования. Так, например, остаются остро дискуссионными отдельные вопросы квалификации данного вида посягательств, что в свою очередь вызывает сложности в правоприменительной практике.

Исследование состава хищения предметов, имеющих особую ценность, и вопросов его квалификации позволяет сделать ряд выводов.

Во-первых, анализ регламентации ответственности за хищение предметов, имеющих особую ценность, в российском уголовном законодательстве позволяет заключить, что современное состояние закона в этой части явилось результатом достаточно длительной эволюции, поскольку прообразы и исторические аналоги соответствующих норм можно найти в достаточно древних памятниках отечественного права. Таким образом, и с точки зрения исторической преемственности, самостоятельная

культурную ценность: Практическое пособие / под общ. ред. С.П. Щерба. М.: Учебноконсультационный центр «ЮрИнфо», 2016. 